\title{
EFFECTS OF DIFFERENT HALF-TIME RE-WARM UP ON VERTICAL JUMP DURING SIMULATED BASKETBALL GAME
}

\author{
Rèjus Pociūnas' ${ }^{1}$ Vytautas Pliauga ${ }^{1,2}$, Inga Lukonaitiené ${ }^{1}$, Dominykas Bartusevičius ${ }^{1}$, \\ Tomas Urbonavičius ${ }^{1}$, Algirdas Stuknys ${ }^{1}$, Jūratė Stanislovaitiené ${ }^{1}$ \\ Lithuanian Sports University ${ }^{l}$, Kaunas, Lithuania \\ Kaunas University of Technology,2, Kaunas, Lithuania
}

\begin{abstract}
Background. This study investigated the acute effects of different half-time re-warm ups on vertical jump height during simulated basketball games.

Methods. Ten college level males (age (mean \pm standard deviation $(S D)$ ), $22.0 \pm 5.0$ years; weight, $86.0 \pm 5.5 \mathrm{~kg}$; height, $193 \pm 1 \mathrm{~cm}$.) were divided into two teams, who played three simulated basketball games with three different type half-time re-warm ups: aerobic; aerobic + post-activation potentiation exercises and aerobic + post-activation potentiation + stabilization exercises. Counter-movement jump was measured before and during the simulated basketball game at seven time points: before and after warm up, after the $1^{\text {st }}$ the $2^{\text {nd }}$ quarters, after re-warm up and after the $3^{\text {rd }}$ and the $4^{\text {th }}$ quarters. Simulated basketball games were separated at least by 72 hours.

Results. The non-significant decrease in Counter-movement jump height during simulated basketball games was observed after executing all three different types of half-time re-warm ups. However, Counter-movement jump significantly $(p<.05)$ decreased during simulated basketball game only in aerobic type half-time re-warm up game.

Conclusion. During simulated basketball game, the least decrease in Counter-movement jump height was observed after aerobic type re-warm up with post-activation potentiation exercises performed at half-time.
\end{abstract}

Keywords: basketball, half-time re-warm up, power, post activation potentiation.

\section{INTRODUCTION}

$\mathrm{B}$ asketball is intermittent team sport, where energy is being received from different energy systems (Jeffreys \& Moody, 2016). Nowadays basketball is regarded as a physically dominant sport, where physical abilities play a huge role in the overall performance (Schelling \& Torres-Ronda, 2013). High-intensity movements in basketball are directly related to the development of power and agility in movement skills (Castagna et al., 2007; Meckel, Casorla, \& Eliakim, 2009). The ability to move quickly and jump as high as possible shows the players' capacity and other technical skills that are important in basketball, i.e. a quick breakthrough, quick advances from defense to attack, sharp jumps, fight for the ball and defense. There is a huge variety of movements, most of which are not only performed repeatedly, but at high intensity as well (Elo \& Svilar, 2016). Strength and conditioning coaches, sport scientists are looking for a way to optimize the performances of basketball players during the game and for each half separately. Therefore, it is necessary to determine, which warm up would prove to be the most effective in terms of movement effectiveness and overall performance. Some authors recommend using alactic type exercises when performing a warm up, i.e. applying muscle post activation potentiation (PAP), others - alactic anaerobic / anaerobic lactic, i.e. between lactate and lactate accumulation threshold. Two warm ups were 
carried out during the simulated basketball game the main warm up that is done before the game and half-time re-warm up. It is equally important to find the optimal warm up not only during the program, but also during the half-time re-warm up.

Warm up not only helps to reduce the risk of injuries but allows players to perform movements more effectively from the very beginning (Edholm, Krustrup \& Randers, 2015). It can be caused by a big variety of biomechanical, physiological and biochemical processes, such as increased flexibility of musculotendinous unit, elevated blood flow to the muscles, increased metabolism, increased conduction of nerve impulse (Bishop, 2003). Even though two warm ups are being performed in the whole basketball game, there is very limited research carried out about half-time re-warm up and its effect on the second half. Taking as an example, football is more advanced in this matter. Mohr, Krustrup, and Bangsbo (2005) carried out a study and found that football players tended to play slower during the second half. The same authors have found that there is increased risk of injuries during the second half, compared to the first half. That being the case, dynamical re-warm up was more effective in terms of power outputs than passive re-warm up during the second half of football match (Edhol at al., 2015).

\section{METHODS}

Subjects. Ten college level males (mean $\pm S D$; age, $22.0 \pm 5.0$ years; weight, $86.0 \pm 5.5 \mathrm{~kg}$; height, $193 \pm 1 \mathrm{~cm}$, training experience, $8.0 \pm 2.9$ years). Participants were free of injuries in the 6 months before the starting of the study. The experiment was performed during the preseason period, during which players trained $1-2 \mathrm{~h}$ per day and 5-6 days per week. Players did not undertake intensive exercise in the $48 \mathrm{~h}$ before each testing session. All players were notified about the aim of the study, research procedures, requirements and benefits.

Procedure. Each team had 5 players and every simulated game was played 5 on 5 - every player played 40 minutes. Simulated games were played following official basketball rules and each team had a basketball coach. The games were played at maximum effort, athletes were motivated verbally in order to make the simulated game more reliable and similar to the official match. Countermovement jump was measured before the warm up, after the warm up, after the first quarter, after the second quarter, after the re-warm up and after the third and fourth quarters. After the first half of the game, tactical simulation was conducted and for 5-8 minutes, athletes listened to the coaches' tactical advice and rested passively. For the rest 7-10 minutes of the half-time, the players executed different types of re-warm up.

Simulated basketball game. The participants were then divided into two teams by the coach. The criteria for a team assignment were the basketball performance level and playing position. The two teams played a simulated game that consisted of four 10-minute quarters with a 15 -minute break at half time and 8-minute breaks after the first and the third quarters. The players usually had a 2- minute break to rest after the first and the third quarters, but the subjects in the present study rested for 2 minutes during those breaks and then performed tests for 6 minutes. The game involved official umpires and took place on an indoor basketball court. Player substitutions were not allowed, and the players stayed in the game even when they had five fouls. This protocol of simulated basketball game was established previously (Pliauga et al., 2015).

Counter-movement jump (CMJ) with arm swing. This test was previously used in basketball to assess vertical jump performance (Boccolini, Brazzit, Bonfanti, \& Alberti, 2013; Nikolaidis, Calleja-González, \& Padulo, 2014). Participants performed vertical jump on a contact mat (Powertimer Testing System, New Test, Oulu, Finland) starting from an upright standing position with preliminary downward movement to a knee angle of approximately $90^{\circ}$ with an arm swing. Three trials were performed with $20 \mathrm{~s}$ of rest between each trial. The best result was used for analysis. If the third trial result was the best, one additional trial was carried out (Pliauga et al., 2015). The height of the jumps was calculated by applying the following equation: $\mathrm{H}=1.226 \mathrm{x}$ Tf2 (m), where Tf = flight time (s) (Bosco, Viitasalo, Komi, \& Luhtanen, 1982). The best result was used for further analysis. The ICC for this test was established previously (0.95; (Kamandulis et al., 2013).

Post activation potentiation (PAP). In order to cause post activation potentiation, participants performed accelerations (4 sets, duration of a repetition 4-7 s) and 5 jumps (60-70-80-90-95 percent). The jumps were performed according to a subjective feeling. 
Table. Different half-time re-warm ups schemes

\begin{tabular}{|c|c|c|c|}
\hline Characteristics & Aerobic & Aerobic + PAP & Aerobic + PAP + stabilization \\
\hline Content & $\begin{array}{l}\text { - Tactical instructions } \\
\text { ( } 7 \text { min); } \\
\text { Jogging; dribbling; } \\
\text { shooting the ball }(8 \\
\text { min) ((heart rate } 130- \\
140 \text { bpm) }\end{array}$ & $\begin{array}{l}\text { - Jogging; dribbling; } \\
\text { shooting the ball; } \\
\text { - Sprints; shuffles; } 5 \text { vertical } \\
\text { jumps }(60,70,80,90,95 \% \\
\text { of maximum effort). }\end{array}$ & $\begin{array}{l}\text { - Jogging; dribbling; shooting the ball; } \\
\text { - Sprints; shuffles; } 5 \text { vertical jumps } \\
(60,70,80,90,95 \% \text { of maximum } \\
\text { effort); Stabilization exercises: leg } \\
\text { flexion/extension; supine bridge with } \\
\text { leg raise. }\end{array}$ \\
\hline $\begin{array}{l}\text { Exercises } \\
\text { typology }\end{array}$ & Continuous & Intermittent & Intermittent \\
\hline Intensity & Low & Submax, $\max$ & Submax, max \\
\hline
\end{tabular}

Heart rate (HR) monitoring and recording. During the half-time re-warm up HR was constantly registered by pulse measuring instrument with memory Polar Team System 2 that registered HR values every five seconds.

Half-time re-warm up. The participants made three different half-time re-warm up: aerobic; aerobic + PAP exercises; aerobic + PAP exercises + stabilization exercises. All characteristics of the half-time re-warm ups were described and carried out in the indicated sequences (Table 1).

Mathematical statistics. The arithmetic mean, standard deviation and percentage change were calculated. The application of the Student's $t$ test revealed a statistically significant difference. The level of alpha statistical significance was set at $p<.05$. The calculations were performed using Microsoft $₫$ Excel program.

\section{RESULTS}

The height of counter-movement jumps before and after different half-time re-warm up is presented in Figure 1. There was a decrease in counter-movement jump after executing all three different type half-time re-warm up, thus, only aerobic type half-time re-warm up showed to decrease counter-movement jump significantly ( $p<$ $.05)$. Nevertheless, vertical jump height decreased after performing aerobic type re-warm up with PAP and aerobic type half-time re-warm up with PAP and stabilization exercises, however in both types of aforementioned re-warm up no significant decreases were found $(p>.05)$.

The height of counter-movement jumps before and after all simulated game quarters are presented in Figure 2. Results were measured before warm

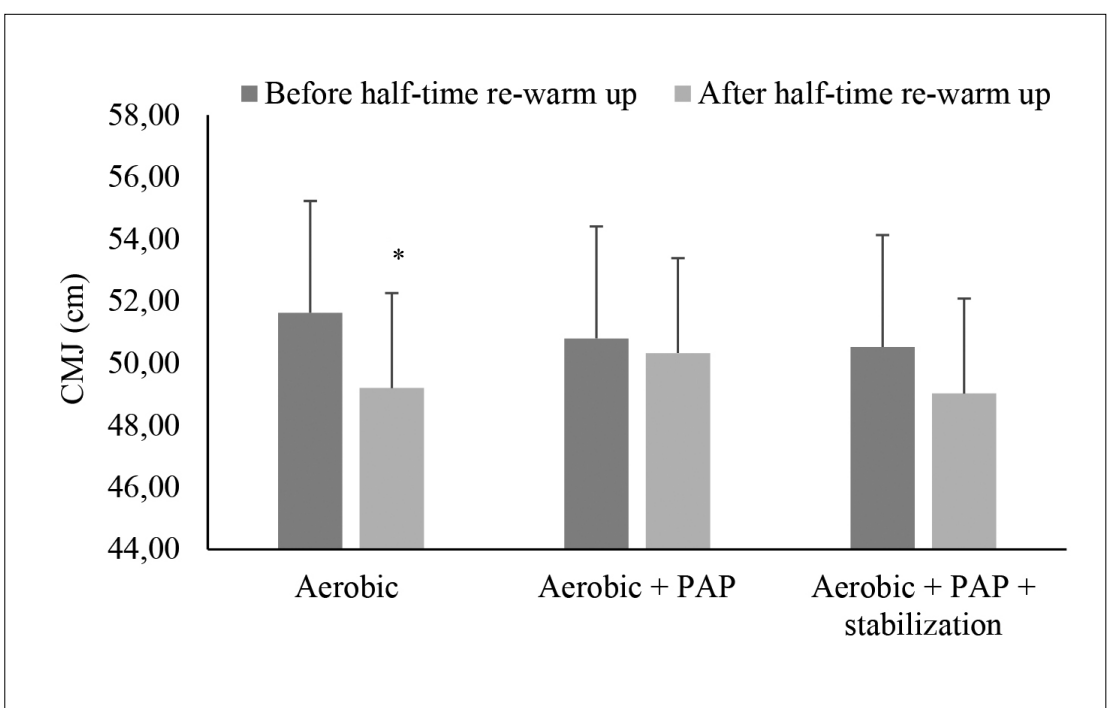

Figure 1. Mean values of countermovement jump before and after different half-time re-warm up (average $\pm S D)$

Note. * - significantly different between results before and after re-warp up. 
Figure 2. Mean values of vertical jump height during the simulated basketbll games after different halftime re-wam up (average \pm $S D)$

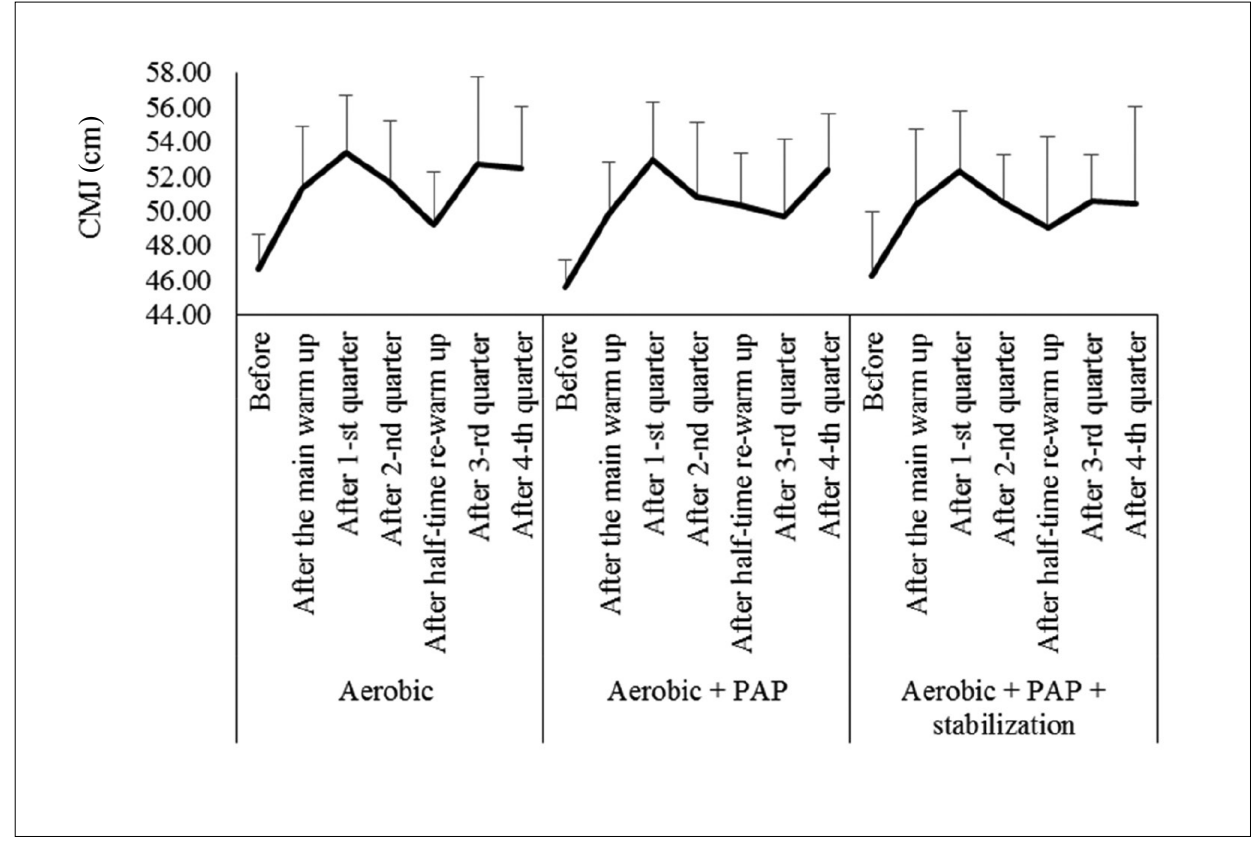

up, after warm up, after the 1st quarter, after the 2nd quarter, after three different types of half-time re-warm up, after the 3rd quarter and after the 4th quarter. Vertical jump height decreased the least after performing an aerobic type re-warm up with PAP.

\section{DISCUSSION}

This study investigated the acute effects of different half-time re-warm up on countermovement jump during simulated basketball games. It was concluded that half-time re-warm up with aerobic and PAP exercises was the most effective because counter-movement jump performance was impaired the least comparing with other two rewarm up regimens.

There is limited research on power indicators after re-warm up in basketball. The topic of rewarm up has been emphasized significantly in football and scientists have shown a clear advantage of this strategy. Based on scientific literature, distance covered in the second half by football players decreases and the speed of running in the first 15 minutes of the second half is significantly slower compared with the first 15 minutes in the first half (Weston et al., 2011). The findings of our study showed similar results as indicated by Weston because independent of applied re-warm up regimens in every case there was reduction in athlete's power indicators after the second half compared with the beginning of the first half. Previous research also supports the idea of higher intensities being produced by the athletes in the first 5 minutes of the first half compared with the first 5 minutes of the second half (Mohr, Krustrup, \& Bangsbo, 2003). The mechanisms underlying power reduction in the second half are not yet fully understood. However, scientists have drawn attention to a couple of hypothesis about tactical aspects of the game: fatigue, length of the half breaks, temperature (Mugglestone, Morris, Saunders, \& Sunderland, 2013; Zois, Bishop, Fairweather, Ball, \& Aughey, 2013). It is a common case that athletes perform warm up before every game, but it is less common for athletes to re-warm up during half time. Having that in mind, researchers noticed $2^{\circ} \mathrm{C}$ reduction of muscle temperature at the beginning of the second half in football (Mohr, Krustrup, Nybo, Nielsen, \& Bangsbo, 2004). Other authors add that adequate rise of muscle temperature promotes potentiation of the nervous system (Gray, De Vito, Nimmo, Farina, \& Ferguson, 2006) which indicates athlete's ability to perform high intensity movements faster and more efficiently (Mohr et al., 2004). The same researchers concluded that reduced muscle temperature in the lower extremities have strong correlation with reduction of maximal sprinting speed, unless muscle temperature during half time break is maintained, in that case athletes maximal sprinting speed remains unchanged. Furthermore, it is important to outline that, during the half-time break using low to moderate intensity re-warm up football players maintain the indicators of countermovement jump and maximal sprint speed during the second half (Edholm et al., 2015). 
Our study revealed that reduction of power before and after re-warm up fluctuated between $0.93-4.8 \%$ depending on re-warm up type. These results are familiar with othrer authors' work Edholm et al. (2015) showed a reduction in countermovement jump height by 7.6 and $3.1 \%$ after passive and low intensity re-warm up respectively. In our study, the indicators after aerobic re-warm up were lower compared with Edholm's results (4.8\%), however it is important to emphasize that these two studies should not be compared equally because re-warm up in Edholm's research was conducted for the whole half break, contrary with our study, where the first 8 minutes of the half time break were used for simulated head coach's tactical suggestions, therefore re-warm up time was shorter.

Reffering to Lovell, Kirke, Siegler, McNaughton, and Greig (2007), power decreased by $6.2 \%$ after repeated 7-minute re-warm up with $70 \%$ of maximum heart rate. The previously mentioned study performed a similar re-warm up compared to our aerobic with PAP re-warm up, however we can only compare these studies theoretically.

Basketball players showed the best power results after aerobic with PAP re-warm up. There is a lot of research of PAP advantage and the authors agree that post-activation potentiation is a phenomenon which could increase muscle power (Wilson et al., 2013). Chiu and colleagues (2003) showed an increase in vertical jump height with arm swing and vertical jump height without arm swing after executing jumps of a platform results by $1-3 \%$ in experienced athletes while doing 5 sets of 1 repetition of squats with 90\% 1RM (1 repetition maximum). Power indicators were the highest right after performing warm up and lowest after the 3rd quarter. Aerobic with PAP re-warm up can influence the results because of additional energy demand. The most effective way to use PAP phenomenon is to find balance between fatigue and potentiation (Tillin \& Bishop, 2009). This balance depends on many factors, such as players training experience (Kilduff et al., 2007), recovery breaks between exercises (Kilduff et al., 2008), intensity and type of exercise (Sale, 2002).

Stabilization is defined as the ability to maintain body balance when the movement changes from dynamic to static (Wikstrom, Tillman, Smith, \& Borsa, 2005). Dynamic stabilization helps athletes to maintain stable body position in specific movements (Bressel, Yonker, Kras, \& Heath, 2007; Kovacs et al., 2008). Stabilization impact on jumping with one leg was investigated only in one study which concluded that dynamic stabilization and jumping with one leg had significant correlation (Lockie, Schultz, Luczo, Callaghan, \& Jeffriess, 2013). Not enough studies have researched the impact of stabilization exercises on vertical jump height.

\section{CONCLUSIONS}

During simulated basketball game the least decrease in counter-movement jump height was observed after aerobic type re-warm up with postactivation potentiation exercises performed at half time. Also, it has to be mentioned that aerobic type re-warm up has maintained greater countermovement results after the $3 \mathrm{rd}$ and the 4 th quarters. Thus, it is recommended that aerobic type re-warm up and basketball-specific exercises should be performed at half time in order to achieve PAP and an increase in muscle temperature. Nevertheless, more research has to be carried out to gain better understanding of the effect of different re-warm up.

Conflict of interests. The authors declare no conflict of interests regarding the publication of this manuscript.

\section{REFERENCES}

Bishop, D. (2003). Warm up I. Sports Medicine, 33(6), 439-454.

Boccolini, G., Brazzit, A., Bonfanti, L., \& Alberti, G. (2013). Using balance training to improve the performance of youth basketball players. Sport Sciences for Health, 9(2), 37-42. doi: 10.1007/s11332-013-0143-z Bosco, C., Ito, A., Komi, P. V., Luhtanen, P., Rahkila, P., Rusko, H., \& Viitasalo, J. T. (1982). Neuromuscular function and mechanical efficiency of human leg extensor muscles during jumping exercises. Acta Physiologica, 114(4), 543-550.
Bressel, E., Yonker, J. C., Kras, J., \& Heath, E. M. (2007). Comparison of static and dynamic balance in female collegiate soccer, basketball, and gymnastics athletes. Journal of Athletic Training, 42(1), 42.

Castagna, C., Manzi, V., D’ottavio, S., Annino, G., Padua, E., \& Bishop, D. (2007). Relation between maximal aerobic power and the ability to repeat sprints in young basketball players. Journal of Strength and Conditioning Research, 21(4), 1172-1176.

Chiu, L. Z., Fry, A. C., Weiss, L. W., Schilling, B. K., Brown, L. E., \& Smith, S. L. (2003). Postactivation 
potentiation response in athletic and recreationally trained individuals. Journal of Strength \& Conditioning Research, 17(4), 671-677.

Edholm, P., Krustrup, P., \& Randers, M. B. (2015). Halftime re-warm up increases performance capacity in male elite soccer players. Scandinavian Journal of Medicine \& Science in Sports, 25(1). doi: 10.1111/sms.12236

Elo, H., \& Svilar, L. (2016). Functional movement preparation. In Game analysis fact (pp. 15). Zagreb, Croatia: BIO TRENING.

Gray, S. R., De Vito, G., Nimmo, M. A., Farina, D., \& Ferguson, R. A. (2006). Skeletal muscle ATP turnover and muscle fiber conduction velocity are elevated at higher muscle temperatures during maximal power output development in humans. American Journal of PhysiologyRegulatory, Integrative and Comparative Physiology, 290(2), R376-R382. doi: 10.1152/ajpregu.00291.2005.

Jeffreys, I., \& Moody, J. (2016). Strength and Conditioning for Sports Performance. Routledge.

Kamandulis, S., Venckūnas, T., Masiulis, N., Matulaitis, K., Balčiūnas, M., Peters, D., \& Skurvydas, A. (2013). Relationship between general and specific coordination in 8-to 17-year-old male basketball players. Perceptual and Motor Skills, 117(3), 821-836. doi: 10.2466/25.30.PMS.117x28z7

Kilduff, L. P., Bevan, H. R., Kingsley, M. I., Owen, N. J., Bennett, M. A., Bunce, P. J., ... Cunningham, D. J. (2007). Postactivation potentiation in professional rugby players: Optimal recovery. Journal of Strength and Conditioning Research, 21(4), 1134.

Kilduff, L. P., Owen, N., Bevan, H., Bennett, M., Kingsley, M. I., \& Cunningham, D. (2008). Influence of recovery time on post-activation potentiation in professional rugby players. Journal of Sports Sciences, 26(8), 795-802. doi: 10.1080/02640410701784517

Kovacs, M. S., Roetert, E. P., \& Ellenbecker, T. S. (2008). Efficient deceleration: The forgotten factor in tennisspecific training. Strength \& Conditioning Journal, 30(6), 58-69. doi: 10.1519/SSC.0b013e31818e5fbc

Lockie, R. G., Schultz, A. B., Luczo, T. M., Callaghan, S. J., \& Jeffriess, M. D. (2013). Effect of unilateral dynamic stability on lateral jump performance in team sport athletes. Serbian Journal of Sports Sciences, 7(4). doi: 10.1007/s11274-015-1903-5

Lovell, R. J., Kirke, I., Siegler, J., McNaughton, L. R., \& Greig, M. P. (2007). Soccer half-time strategy influences thermoregulation and endurance performance. Journal of Sports Medicine and Physical Fitness, 47(3), 263-269.

Meckel, Y., Casorla, T., \& Eliakim, A. (2009). The influence of basketball dribbling on repeated sprints. International Journal of Coaching Science, 3(2), 43-56. doi: 10.1007/s11274-015-1903-5

Mohr, M., Krustrup, P., \& Bangsbo, J. (2003). Match performance of high-standard soccer players with special reference to development of fatigue. Journal of Sports Sciences, 21(7), 519-528. doi: 10.1080/0264041031000071182
Mohr, M., Krustrup, P., \& Bangsbo, J. (2005). Fatigue in soccer: A brief review. Journal of Sports Sciences, 23(6), 593-599. doi: 10.1080/02640410400021286

Mohr, M., Krustrup, P., Nybo, L., Nielsen, J. J., \& Bangsbo, J. (2004). Muscle temperature and sprint performance during soccer matches-beneficial effect of re-warm up at half-time. Scandinavian Journal of Medicine \& Science in Sports, 14(3), 156-162. doi: 10.1046/j.1600-0838.2003.00349.x

Mugglestone, C., Morris, J. G., Saunders, B., \& Sunderland, C. (2013). Half-time and high-speed running in the second half of soccer. International Journal of Sports Medicine, 34(06), 514-519. doi: 10.1055/s-0032-1327647 Nikolaidis, P., Calleja-González, J., \& Padulo, J. (2014). The effect of age on positional differences in anthropometry, body composition, physique and anaerobic power of elite basketball players. Sport Sciences for Health, 10(3), 225-233. doi:10.1007/ s11332-014-0198-5

Pliauga, V., Kamandulis, S., Dargevičiūtè, G., Jaszczanin, J., Klizienè, I., Stanislovaitienè, J., \& Stanislovaitis, A. (2015). The effect of a simulated basketball game on players' sprint and jump performance, temperature and muscle damage. Journal of Human Kinetics, 46(1), 167-175. doi: 10.1515/hukin-2015-0045

Sale, D. G. (2002). Postactivation potentiation: Role in human performance. Exercise and Sport Sciences Reviews, 30(3), 138-143.

Schelling, X., \& Torres-Ronda, L. (2013). Conditioning for basketball: Quality and quantity of training. Strength \& Conditioning Journal, 35(6), 89-94. doi: 10.1519/ SSC.0000000000000018

Tillin, N. A., \& Bishop, D. (2009). Factors modulating post-activation potentiationand its effect on performance of subsequent explosive activities. Sports Medicine, 39(2), 147-166.

Weston, M., Batterham, A. M., Castagna, C., Portas, M. D., Barnes, C., Harley, J., \& Lovell, R. J. (2011). Reduction in physical match performance at the start of the second half in elite soccer. International Journal of Sports Physiology and Performance, 6(2), 174-182. doi: 10.1123/ijspp.6.2.174

Wikstrom, E. A., Tillman, M. D., Smith, A. N., \& Borsa, P. A. (2005). A new force-plate technology measure of dynamic postural stability: The dynamic postural stability index. Journal of Athletic Training, 40(4), 305.

Wilson, J. M., Duncan, N. M., Marin, P. J., Brown, L. E., Loenneke, J. P., Wilson, S. M., ... Ugrinowitsch, C. (2013). Meta-analysis of postactivation potentiation and power: Effects of conditioning activity, volume, gender, rest periods, and training status. The Journal of Strength \& Conditioning Research, 27(3), 854-859.

Zois, J., Bishop, D., Fairweather, I., Ball, K., \& Aughey, R. J. (2013). High-intensity re-warm-ups enhance soccer performance. International Journal of Sports Medicine, 34(09), 800-805. doi: 10.1055/s-008-40455 